\title{
Vehicle tracks are predator highways in intact landscapes
}

Keren G Raiter ${ }^{\mathrm{a}, \mathrm{b}, \mathrm{c}, \mathrm{d}}$, Richard J Hobbs ${ }^{\mathrm{b}}$, Hugh P Possingham ${ }^{\mathrm{e}, \mathrm{d}}$, Leonie E Valentine ${ }^{\mathrm{b}}$, and Suzanne M Prober $^{\mathrm{b}, \mathrm{c}}$

a Department of Ecology, Evolution and Behavior, Hebrew University of Jerusalem, Givat Ram, Jerusalem, Israel

${ }^{\mathrm{b}}$ School of Biological Sciences, University of Western Australia, 35 Stirling Hwy Crawley, Perth, WA, 6009, Australia

c CSIRO Land and Water, Private Bag 5, Wembley, WA, 6913, Australia

d School of Biological Sciences, University of Queensland St Lucia, Brisbane, Qld, 4072, Australia

e The Nature Conservancy, 4245 North Fairfax Drive, Suite 100 Arlington, VA, 22203, USA

Corresponding author: Keren Raiter, Department of Ecology, Evolution and Behavior, Hebrew University of Jerusalem, Givat Ram, Jerusalem, Israel. Email: keren.raiter@mail.huji.ac.il / keren.raiter@me.com

Citation for this article: Raiter, K.G., Hobbs, R., Possingham Hugh, P., Valentine, L.E., Prober, S.M., 2018. Vehicle tracks are predator highways in intact landscapes. Biological Conservation.

https://doi.org/10.1016/i.biocon.2018.10.011.

C 2018. This manuscript version is made available under the CC-BY-NC_ND 4.0 licence

https://creativecommons.org/licenses/by-nc-nd/4.0/

\section{Abstract}

Roads and other forms of linear infrastructure are rapidly proliferating worldwide, yet little is known about how roads affect the distribution and abundance of predators, particularly in relatively intact landscapes. We used a combination of motion-sensor cameras and spoor surveys to compare dingo, fox and feral cat activity on unsealed vehicle tracks (hereafter: roads) and up to 3 kilometres away, in relatively intact landscapes of the Great Western Woodlands in south-western Australia. We compared predator activity as indicated by independent sightings and spoor observations, in woodlands and shrublands: vegetation types with contrasting permeabilities.

Predator activity was observed between 12 and 261 times more frequently on roads compared with offroad for all species studied. Roads also appeared to affect predator activity up to $2.5 \mathrm{~km}$ away. Even poorly formed and abandoned roads concentrated predator activity and affected landscape-scale rates of predator observations. The effect of road proximity on predator activity was non-linear and different between vegetation types for dingoes and cats but not foxes. Our results provide new evidence of the effects of roads on predator activity in surrounding landscapes, with interacting effects of vegetation. They also reinforce previous findings e.g. stronger roads preference displayed by dingoes and foxes, than by cats. Roads and other linear infrastructure have strong effects on predator activity within intact landscapes, although further research is needed to characterise the implications for prey species. Road planning or approvals, as well as habitat restoration programs for threatened species, should account for the effects of roads on predator activity. 


\section{Keywords}

Ecological impacts; Great Western Woodlands; linear infrastructure; predation; road ecology; road effect zone.

\section{Highlights}

- Roads are proliferating globally but impacts on predator activity are not well known

- We assessed dingo, cat and fox activity on- and for up to $3 \mathrm{~km}$ off-roads

- Activity was between 12 and 261 times greater on roads compared with off-road

- Motion-cameras yielded different results to scats \& print surveys

- These results have global ramifications, but can inform mitigation and conservation

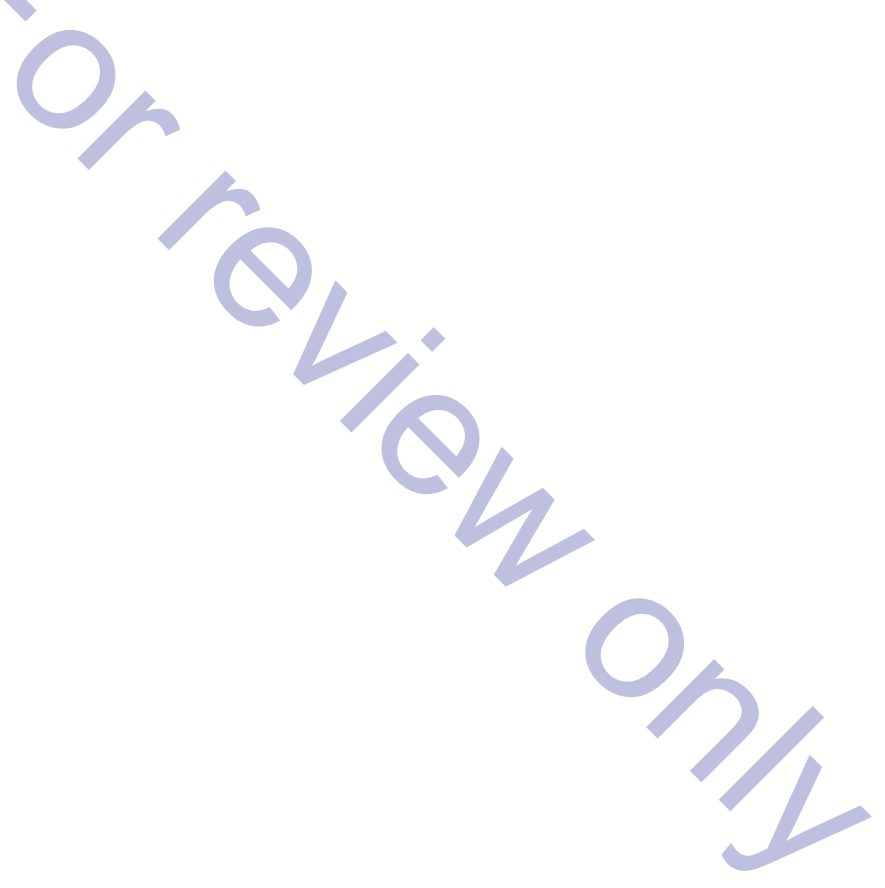




\section{Introduction}

Rapid global growth in linear infrastructure (e.g. roads) threatens detrimental impacts on surrounding ecosystems (Laurance 2018). Avoiding, mitigating and/or offsetting these impacts requires a solid understanding of their wide-ranging ecological effects (van der Ree et al. 2015a). Roads that penetrate into relatively intact areas often have disproportionately large consequences for affected ecosystems (Laurance et al. 2015). However, the landscape-scale effects of roads are poorly characterised and largely neglected in environmental impact evaluations (Jaeger 2015). In this paper, we examine how unsealed vehicle tracks in relatively intact landscapes affect predator activity at a landscape scale.

Roads in otherwise intact landscapes can have a plethora of impacts on the ecosystems they pass through, with evidence emerging for changes in microclimate, facilitation of exotic invasions, edge effects, modifications to organism movements and effects on hydrological flows (Forman et al. 2003; van der Ree et al. 2015b; Raiter et al. 2018b). Predation is a key ecosystem process regulating fauna populations with follow-on effects for other trophic levels and processes (Laundré et al. 2013). Excess predation can be severely detrimental to populations and ecosystems, especially in the case of invasive mammalian predators which are one of the major threats to biodiversity globally (Salo et al. 2007). Changes in predator activity in relation to roads have been informally observed in many systems, but such changes have rarely been systematically evaluated and knowledge on the effect of roads and other linear infrastructure on landscape scale predation processes remains limited (May \& Norton 1996; Basille et al. 2013; Doherty et al. 2015). In particular, little is known about predator use of roads compared to surrounding vegetation matrices, and the influence of other factors such as vegetation and traffic.

Roads and other linear clearings can act as movement pathways or provide for improved access, and/or visibility and more efficient hunting and travel (James 1999; Doherty et al. 2015). Where animals use roads, roads have been found to increase habitat permeability and stimulate greater movement rates resulting in greater rates of prey encounter for predators (James 1999; Avgar et al. 2013). For example, James and Stuart-Smith (2000) found that wolves tend to be more common closer to roads and that caribou are at higher risk of predation when they are close to roads. Similarly, DeGregorio et al. (2014) found that rat snakes were frequently associated with unpaved road edges and that as a consequence, the distance to an unpaved road strongly influenced nestling survival for birds that they prey on.

Although a number of studies have demonstrated the use of roads by mammalian predators, few have compared on-road activity with off-road activity (e.g. Cavallini 1994; Read \& Eldridge 2010). Some predators, including jaguars and pumas, have been found to preferentially use roads to varying extents (Harmsen et al. 2010), while others such as lynx and black, brown and grizzly bears have been found to avoid roads (Brody \& Pelton 1989; Dixon 1997; Suring et al. 1998; Basille et al. 2013; Grilo et al. 2015). 
There is mixed evidence regarding road use by other species such as feral cats (Read \& Eldridge 2010; D. Algar pers. comm. Department of Biodiversity, Conservation and Attractions) and wolves (Mech et al. 1988; Latham et al. 2011), although for the latter, there may be other factors involved that explain these differences, such as land use and human hunting pressure. Factors that may affect the use or avoidance of roads and adjacent areas include traffic levels, traffic speed, habitat structure and density; lunar illumination; human activity; and interspecific interactions, both between different predator species, as well as between predators and prey (Brook et al. 2012; Avgar et al. 2013; Prugh \& Golden 2014; Palmer et al. 2017).

We used motion-sensor cameras and spoor inspections to quantify predator activity on, and for up to 3 $\mathrm{km}$ away from, unsealed vehicle tracks (hereafter: roads) in relatively undisturbed landscapes of the globally significant Great Western Woodlands region in south-western Australia. We investigated the activity of one native apex predator, the dingo (Canis lupus dingo) and two invasive mesopredators, the feral cat (Felis catus) and the red fox (Vulpes vulpes) in two different vegetation types (woodland and shrubland) with contrasting structure and permeability.

We hypothesised that for all three species, 1) on-road activity would be higher than off-road activity; 2) activity would be elevated near a road and reach a lower 'background level' at greater distances from the road; and 3) these effects would be more pronounced in shrublands, where vegetation density at predatorheight is high and the advantages of travelling by road may be greatest, compared to woodlands which have generally open understories.

\section{Methods}

\subsection{Study area}

Our work was conducted in the western half of the Great Western Woodlands (Fig. 1), a region dominated by a relatively intact mosaic of eucalypt woodlands, thickets, and shrublands interspersed with salt lakes and banded ironstone formations. This region is the largest and most intact temperate woodland remaining on Earth at 16 million hectares in size; and comprises a refuge to over 300 vertebrate species, including many that have declined or become locally extinct elsewhere (Watson et al. 2008). Apart from a few small towns, the region has remained largely uncleared and undisturbed except for the effects of pastoralism (approximately one-third of the region) and extensive resource extraction operations, along with changing fire regimes and the effects of invasive species (Prober et al. 2012; Raiter et al. 2017). The Great Western Woodlands offers a model system for investigating the effects of roads within natural habitats on predator activity, as it has an extensive network of roads surrounded by relatively undisturbed landscapes (Raiter et al. 2017). The region also offers contrasting vegetation types to allow exploration of 
habitat influences on road effects. Dingoes, cats and foxes are the three dominant mammalian predators in the region (Watson et al. 2008), further research is required into the consequences Note that there is some hybridisation between dingoes and ex-domestic feral dogs (Canis lupus familiaris), although research has found dingo purity in this area to be high (Stephens 2015).

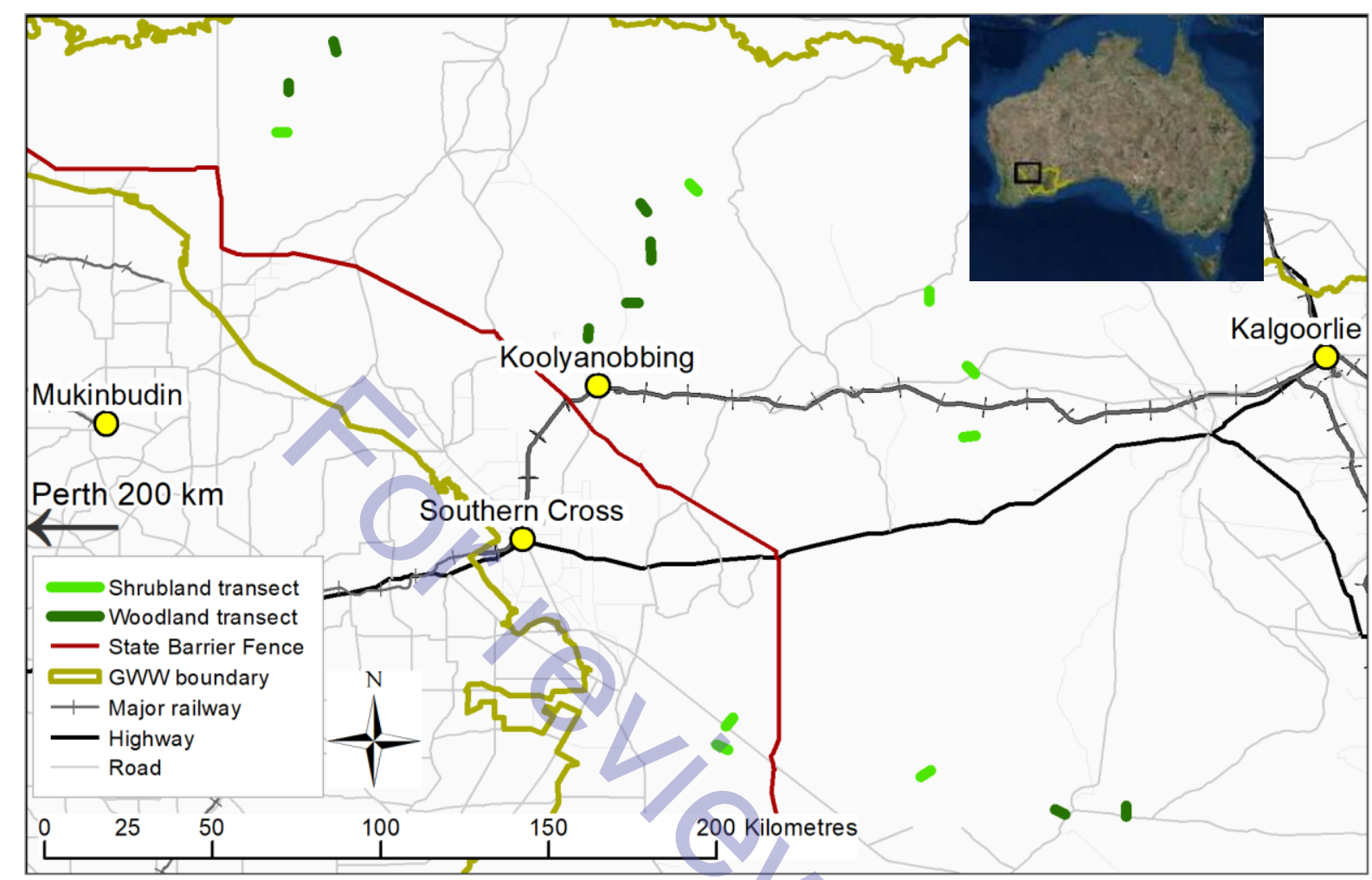

Figure 1: Map of study area showing transects by vegetation type. Major highways and roads are shown, along with the State Barrier Fence, a fence originally established to keep rabbits from invading westward but now used to keep dingoes and other wild dogs as well as emus out of the agricultural area to the west. The two transects west of the fence were established following recommendation by a wild dog control personnel (McEwan pers. comm.) who was aware of dingo activity in that area (a nature reserve) and did not conduct wild dog control activities there at that time. Dingoes were observed at both of these transects. Note that as per Raiter et al. (2017), many of the smaller roads have not been mapped.

We established 16 transects, each starting at a road and extending perpendicularly for three kilometres into the surrounding vegetation. The roads varied from poorly formed vehicle tracks consisting of two wheel ruts, to graded, maintained tracks and all had low to very low traffic levels (average 7.3 vehicles per month (s.d. 14.3); Fig. 2a-b). Transects were placed in either woodland vegetation $(n=8)$, with relatively open understory, or shrublands ( $n=8$ ) with low, dense vegetation (Fig. $2 c-d)$.

Transects were located in generally flat tracts of relatively homogenous vegetation as identified by aerial images. Transects were situated with either no landscape features (e.g. rocky outcrop, salt lake) that may affect predator activity within $3 \mathrm{~km}$, or such that the distance of these features was roughly the same along the whole transect so as not to bias predator activity in relation to the road. Similarly, anthropogenic disturbances (other than the study road) were avoided by at least $3 \mathrm{~km}$ (often $>10 \mathrm{~km}$ ), although some old, 
overgrown, exploration tracks were found along the study transects: these could not be entirely avoided. Similarly, we avoided areas subject to 'pest control', including trapping and baiting for wild dog and/or aerial cat baiting by at least $3 \mathrm{~km}$.

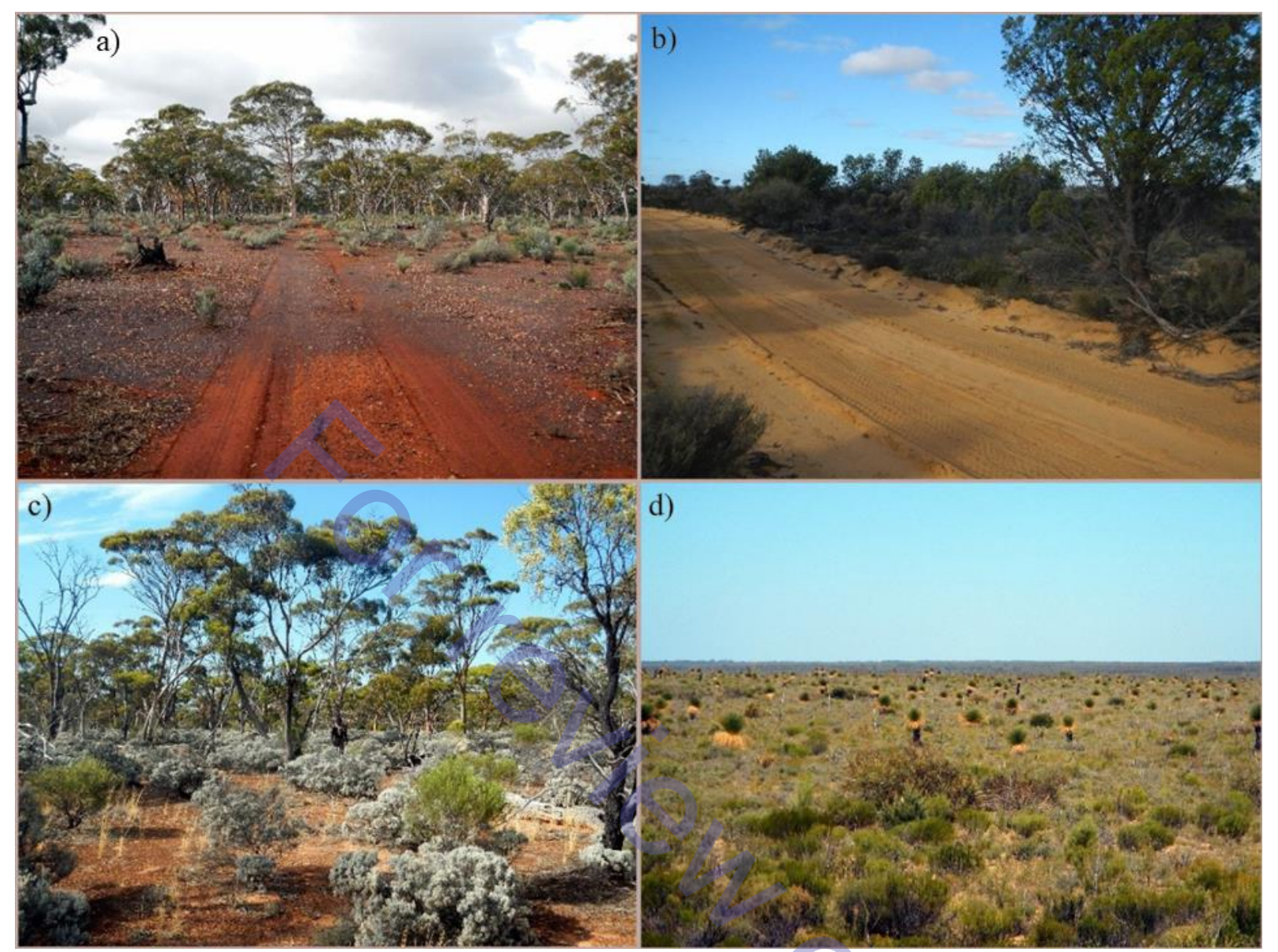

Figure 2: Examples of vehicle tracks and vegetation types used in this study. a) unbladed track consisting of two wheel ruts b) maintained vehicle track c) woodland vegetation with relatively open understorey d) recently-burnt shrubland with relatively dense ground storey.

Transects were generally spaced at least $7 \mathrm{~km}$ apart (or $>14 \mathrm{~km}$ apart in the single case where two transects were placed on the same road) to ensure independence, with one exception where two transects were placed $4.7 \mathrm{~km}$ apart, although they were still $>7 \mathrm{~km}$ apart by road. Transect length, spacing and buffer widths were determined as a compromise between optimal lengths based on average estimated widths of target species home ranges, and logistics. Dingoes, cats and foxes are estimated to have home ranges that average 3-300, 1-23, and 2-7 km wide, respectively (Meek \& Saunders 2000; Fleming et al. 2001; Molsher et al. 2005; Carter et al. 2012; Bengsen et al. 2016). Thus, transects are likely to extend beyond at least the lower estimate of a home range for all species. Vehicle traffic was recorded and included in the analysis of both camera and spoor datasets. 


\subsection{Assessing predator activity}

\section{Motion-sensor cameras}

At each transect, five camera monitoring stations were established: the first on-road and the rest at stratified random distances from the road as follows: off-road camera position 1: 50-200 m; position 2: 200-1000 m, position 3: 1000-2500 m; and position 4: 2500-3000 m. Forty Reconyx (Holmen, Wisconsin, USA) HC600 Hyperfire No-Glow Covert Infrared cameras were rotated between the 80 camera stations over 12 months from July 2013 to July 2014 such that each transect was monitored for two out of four monitoring periods, for an average total of 174 nights per camera. Monitoring was always divided evenly between the vegetation types and the pattern of monitoring was varied for each transect to minimise seasonal biases in the data. Individual cameras were rotated between the different positions within transects to minimise the effect of any variations in camera performance on results. Additional data from a one-month pilot run in June 2013 on one woodland and one shrubland transect were incorporated into the final dataset.

Cameras were attached to star pickets or trees 70-75 cm above ground (to see over low-growing shrubs), approximately facing south and at an angle of 0 to $-5^{\circ}$ to the horizontal. On-road cameras were placed within $1 \mathrm{~m}$ of the road edge and at an angle of approximately $25^{\circ}$ degrees to it, as per Meek et al. (2012). Where vegetation obscured part of the camera detection zone (all shrubland sites), the vegetation was pruned such that at least $80 \%$ of the detection zone was evident; equalising detectability across cameras. Cameras were set on high sensitivity and fast shutter speed and programmed to take five rapid-fire pictures per trigger. We considered observations as being independent when separated by more than 30 minutes, unless we could distinguish multiple individuals.

\section{Spoor surveys}

Visual inspections for animal spoor were conducted on foot along the full length of each transect in January, March-April and July 2014. One transect could not be surveyed in the March survey due to fallen trees blocking the access road. KR examined the ground on $2 \mathrm{~m}$ of each side of the walked route and recorded the location of all predator spoor (prints, scats or other evidence of species presence) observed, using a hand-held GPS. Spatial data was collated in ArcGIS 10.3. Road widths were measured and any spoor on a $10 \mathrm{~m}$ strip of road immediately adjacent to the transect was also recorded at the start of each transect spoor inspection. Spoor was identified to species using advice from experienced local wild dog control personnel and with reference to Triggs (2005) and Moseby et al. (2009). All predator scats were collected and sent to a scatologist for confirmatory identification (G. Storey; Scats About, Australian National University). 


\subsection{Data analysis}

We analysed the camera and spoor datasets separately. Due to the scarcity of data, spoor data from the different spoor surveys were pooled across visits, as were camera data from the different monitoring periods. Pooling the data was based on the assumption that while predator activity may vary from season to season, the effect of roads on predator activity will be consistent across the seasons (as per Cavallini 1994; Read \& Eldridge 2010; Brook et al. 2012, who did not report seasonal shifts and reported other spatial trends being consistent throughout the year). To explore correlates of predator activity, we built generalised additive mixed models (GAMMs) using the 'mgcv' package (version 1.8-7; Wood 2006, 2011) in $R$ version 3.2.1 (R Core Team 2018). We used GAMMs rather than assuming linear fits, as scatterplots indicated non-linear relationships between predator activity and road proximity. Numbers of monitored nights and area surveyed, for the camera and spoor data respectively, were included in the models as offsets for monitoring effort. Transect identity was included as the random factor. Due to the large number of zeros in our datasets, we assessed the need for zero-inflated models by comparing distributions of onroad and off-road datasets with randomly generated data produced by a Poisson process given an identical lambda $(\lambda)$ parameter. We also compared Poisson and Zero-inflated models, and in both cases found that Poisson models were adequate and that overdispersion was not a significant issue according to model evaluation.

For each response variable (i.e. counts of predator observations and observation type combination) with at least 20 observations, we created mixed-effects models using all possible combinations of the four potential predictor variables: on/off road status, road proximity (fitted using thin-plate regression splines), vegetation type and traffic. We also included an 'intercept only' model and models with two-way interactions between road proximity and vegetation type; on/off road status and vegetation type; and on/off road status and traffic, and ran each set of models with varying degrees of flexibility allowed in the smoothing spline ( $k$ values $3,4,5$ and unrestrained). The final optimal and top-ranking models were selected using AIC from all available models.

The spoor data was collated using a range of transect segment sizes (100, 250, 500 and 1000m, giving 496, 208, 112 and 64 observations per species, respectively) and the full set of models was built using each segment-size dataset, to identify the optimal resolution for analysis. Only the most indicative models are presented here. The camera data consisted of 80 data points per species, reflecting the 80 camera stations. We used proportion of null deviance explained (hereafter: deviance explained) as a measure of goodness of fit as it is more appropriate than $\mathrm{R}$ squared for non-normal errors, but we also present adjusted $\mathrm{R}^{2}$ values for each model. Null deviance is computed taking account of any offset, so deviance explained can be substantially lower than R squared when an offset is present (Wood 2006). All datasets produced and 
analysed in the course of this study are available online at https://doi.pangaea.de/10.1594/PANGAEA.895344 (Raiter et al. 2018a).

\section{Results}

We recorded 135 independent predator observations by motion-sensor camera over 13950 trap nights and 110 independent predator spoor (11, 13 and 31 prints, and 9, 31 and 15 scats for dingoes, cats and foxes respectively) over approximately $1130000 \mathrm{~m}^{2}$ of spoor survey (Fig. 3; Table 1).

We found evidence for predator activity on every $(10 \mathrm{~m})$ segment of road studied and there was a stark contrast between on-road and off-road predator activity. Predators were observed at $88 \%$ of on-road cameras and only at $20 \%$ of off-road cameras, with up to 25 and 2 sightings per camera station on-road, and off-road, respectively. The contrast is even greater for the spoor data: an average of 91 predator spoor per hectare were recorded on-road, compared to 0.97 predator spoor per hectare off-road - a hundredfold difference.

Dingoes dominated on-road predator activity, being present on roads in 11 out of the 16 transects and accounting for $80 \%$ of all on-road predator activity observed. Overall, cats were the most ubiquitous predators, with evidence of their activity found on all 16 transects. Evidence of dingo and fox activity was found on 13 and 12 transects respectively; and there were either dingos or foxes, or both, on every transect. Transect random effects were significant in all top-ranking dingo and fox models as well as in most cat models.

The camera and spoor datasets varied considerably, both in numbers of observations and in the trends they indicated, although there were some clear correlations. Table 1 shows summaries of the data by vegetation and distance from road for the different datasets. Predator activity was generally well described by the different models examined, with the top-ranking models explaining $49-96 \%$ of the null deviance (Table 2). 

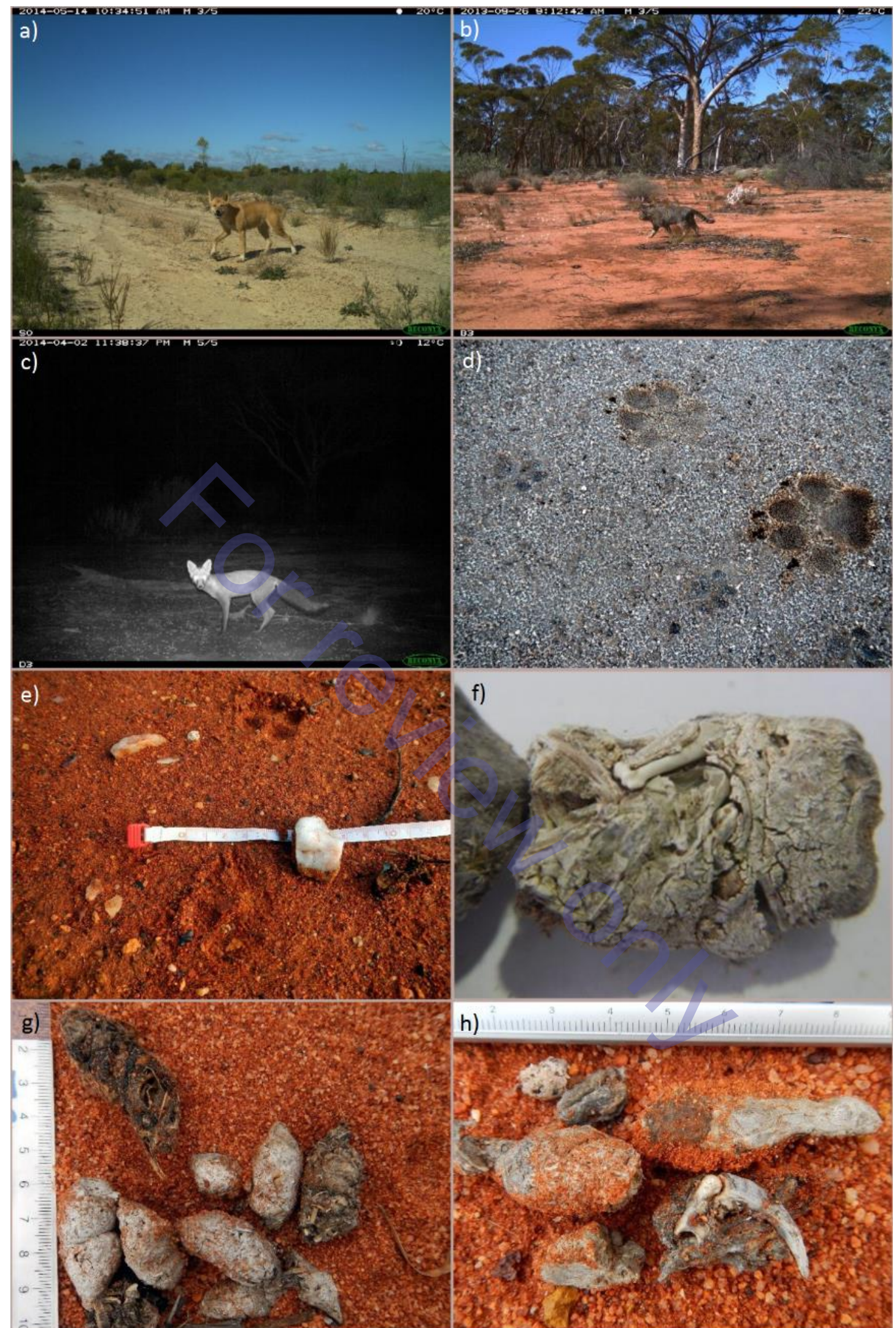

Figure 3: Examples of motion-sensor camera sightings of study species, and spoor observed. a) Dingo on shrubland road. b) Feral cat in woodland, $\sim 1700$ away from road. c) Red fox in woodland, $1950 \mathrm{~m}$ from road. d) (Larger) dingo and (smaller) cat prints going in opposite directions. e) Fox print. f) Feral cat scat showing remains of the Ash-grey mouse (Pseudomys albocinereus). g) Fox scats with remains of cat, reptiles, beetles and centipedes in contents. $h$ ) Dingo scat with large claw protruding. 
Table 1: Summary of predator observations by vegetation type and distance from road, collected via a) motion-sensor cameras and b) spoor surveys (scat and print observations combined). 8 transects were monitored for each vegetation type in both datasets.

\begin{tabular}{|c|c|c|c|c|c|c|c|c|c|c|c|c|c|c|c|c|c|c|c|c|c|c|c|}
\hline \multicolumn{24}{|c|}{ a) observations on motion-sensor cameras } \\
\hline \multirow{2}{*}{$\begin{array}{l}\text { Distance } \\
\text { from } \\
\text { road }\end{array}$} & \multicolumn{4}{|c|}{ on-road } & \multicolumn{3}{|c|}{$50-200 \mathrm{~m}$} & \multicolumn{4}{|c|}{$200-1500 \mathrm{~m}$} & \multicolumn{4}{|c|}{$1500-2500 \mathrm{~m}$} & \multicolumn{4}{|c|}{$2500-3000 \mathrm{~m}$} & \multicolumn{4}{|c|}{ Total } \\
\hline & 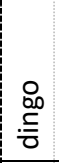 & & . & 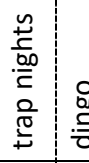 & 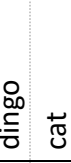 & $\stackrel{\times}{\circ}$ & 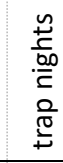 & $\begin{array}{l}\stackrel{\circ}{\circ} \\
\stackrel{2}{5}\end{array}$ & 艹 & $\stackrel{x}{e}$ & 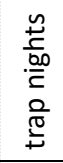 & $\begin{array}{l}\stackrel{\circ}{\circ} \\
\text { : } \\
\frac{\stackrel{0}{0}}{0}\end{array}$ & 莕 & $\stackrel{x}{0}$ & 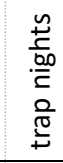 & & त्ष & & 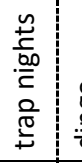 & & ثै ؛ & & 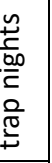 \\
\hline $\begin{array}{l}\text { Wood- } \\
\text { land }\end{array}$ & 20 & 2 & 2 & $\underset{\sim}{\stackrel{\sim}{\sim}}{ }^{2}$ & 1 & 0 & $\underset{\sim}{\stackrel{\sim}{~}}$ & 0 & 0 & 0 & $\underset{\sim}{\stackrel{\sim}{\sim}}$ & 0 & 4 & 1 & $\underset{\sim}{\stackrel{\sim}{J}}$ & 0 & 0 & 0 & $\underset{\sim}{\stackrel{\mathscr{J}}{*}}$ & 227 & 3 & & ఫે \\
\hline $\begin{array}{l}\text { Shrub- } \\
\text { land }\end{array}$ & 85 & 10 . & 1 & 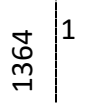 & 1 & 0 & $\stackrel{\infty}{\stackrel{m}{\rightarrow}}$ & 1 & 0 & 0 & $\stackrel{m}{\stackrel{m}{\sim}}$ & 0 & 2 & 0 & $\stackrel{m}{\underset{f}{\sim}}$ & 0 & $2 c$ & 0 & $\left.\underset{\sim}{\stackrel{m}{q}}\right|^{8}$ & 371 & 51 & & ્ָ \\
\hline 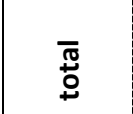 & $\stackrel{n}{\stackrel{n}{\sim}}$ & 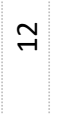 & m & $\stackrel{\circ}{\stackrel{\circ}{\sim}}$ & $m \sim$ & & & -1 & $\circ$ & 0 & $\stackrel{\hat{n}}{\sim}$ & 0 & 6 & -1 & 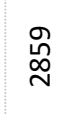 & 0 & $N$ & $\circ$ & 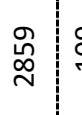 & :े & ก & & 宓 \\
\hline \multicolumn{24}{|c|}{ b) spoor observations } \\
\hline \multirow{2}{*}{$\begin{array}{l}\text { Distance } \\
\text { from } \\
\text { road }\end{array}$} & \multicolumn{4}{|c|}{ on-road } & \multicolumn{5}{|c|}{$0.1-1000 \mathrm{~m}$} & \multicolumn{5}{|c|}{$1000.1-2000 \mathrm{~m}$} & \multicolumn{4}{|c|}{$2000.1-3000 \mathrm{~m}$} & \multicolumn{5}{|c|}{ Total } \\
\hline & 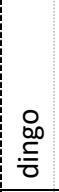 & 芜 & 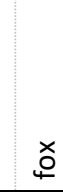 & 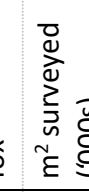 & : & $\begin{array}{l}\text { : } \\
\text { 咅 } \\
\end{array}$ & 艹 & $\stackrel{x}{\stackrel{x}{c}}$ & 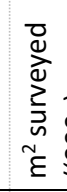 & 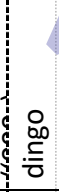 & 芯 & ch & 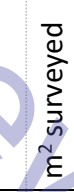 & & & సٓ & $\stackrel{x}{\stackrel{x}{e}}$ & 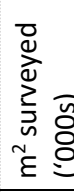 & ơ. & 苧 & 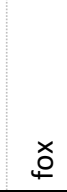 & & 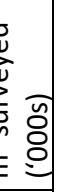 \\
\hline $\begin{array}{l}\text { Wood- } \\
\text { land }\end{array}$ & 2 & 1 & 8 & 0.91 & 10 & & 145 & 5 & 184 & 4 & 15 & 12 & 18 & & 8 & & 15 & 184 & 13 & 38 & 40 & 55 & 53 \\
\hline $\begin{array}{l}\text { Shrub- } \\
\text { land }\end{array}$ & 4 & 1 & 1 & 0.95 & 5 & 1 & 1 & o & 192 & 0 & 3 & 4 & 192 & 22 & & & & & 7 & 6 & 6 & 57 & 77 \\
\hline गुँ & 6 & $\sim$ & $\sigma$ & 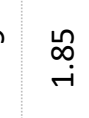 & 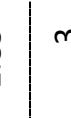 & $n$ & $\stackrel{n}{\sim}$ & in & 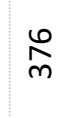 & 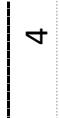 & $\stackrel{\infty}{\sim}$ & $\stackrel{\varphi}{\sim}$ & $\stackrel{\varphi}{\infty}$ & o & r & a & & & 구 & F & $\mathscr{f}$ & & 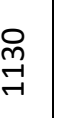 \\
\hline
\end{tabular}


Table 2: Relationships of predator activity to predictor variables in the top-ranking generalised additive mixed models for dingo, cat and fox activity, offset by trap-nights or area as appropriate. Models were selected using AIC; the most parsimonious model in each case is shown in bold.

\begin{tabular}{|c|c|c|c|c|c|c|c|}
\hline $\begin{array}{l}\text { Response } \\
\text { variable }^{1}\end{array}$ & $\begin{array}{l}\text { On-road } \\
\text { mean } \\
\text { estimated } \\
\text { effect (s.e.) }\end{array}$ & $\begin{array}{l}\text { Road } \\
\text { proximity }{ }^{2}\end{array}$ & $\begin{array}{l}\text { Vegetation: } \\
\text { woodland mean } \\
\text { estimated effect } \\
\text { (s.e.) }\end{array}$ & $\begin{array}{l}\text { traffic }^{3} \\
\text { estimated } \\
\text { effect (s.e.) }\end{array}$ & $d f^{4}$ & $\begin{array}{l}\text { deviance } \\
\text { explained } \\
\left(\text { adj. } R^{2}\right)\end{array}$ & $\Delta \mathrm{AIC}$ \\
\hline \multirow{4}{*}{$\begin{array}{l}\text { Dingo } \\
\text { sightings on } \\
\text { camera }\end{array}$} & $119(1.7)$ & $n / a^{5}$ & - & - & 15.92 & $96 \%(0.99)$ & 0.0 \\
\hline & $119(1.7)$ & $n / a^{5}$ & $0.2(108.6)$ & - & 15.92 & $96 \%(0.99)$ & 0.01 \\
\hline & $119(1.7)$ & $n / a^{5}$ & - & $0.78(241)$ & 15.96 & $96 \%(0.99)$ & 0.07 \\
\hline & 119 & $n / a^{5}$ & $0.2(166.5)$ & $1.38(256)$ & 15.97 & $96 \%(0.99)$ & 0.07 \\
\hline \multirow{3}{*}{$\begin{array}{l}\text { Dingo spoor } \\
(100 \mathrm{~m} \\
\text { transect } \\
\text { segments, } \\
\left.\mathrm{k}^{6}=5\right)\end{array}$} & $601(4.8)$ & spline $^{7}$ & $\begin{array}{l}\text { spline } \\
\text { interaction }\end{array}$ & - & 14.65 & $59 \%(0.27)$ & 0.0 \\
\hline & $525(4.7)^{8}$ & spline & spline interaction & $-0.91(3.7)$ & 17.98 & $62 \%(0.31)$ & 0.68 \\
\hline & $603(4.7)$ & spline & spline interaction & $0.74(2.7)$ & 16.61 & $61 \%(0.30)$ & 0.79 \\
\hline \multirow{3}{*}{$\begin{array}{l}\text { Cat sightings } \\
\text { on camera } \\
\left(\mathbf{k}^{6}=4\right)\end{array}$} & - & spline $^{7}$ & spline interaction 7 & - & 9.24 & $58 \%(0.47)$ & 0.0 \\
\hline & $0.35(3.4)$ & spline & spline interaction & - & 10.39 & $59 \%(0.48)$ & 1.00 \\
\hline & - & spline & spline interaction & $0.77(2.2)$ & 10.41 & $58 \%(0.49)$ & 1.74 \\
\hline \multirow{9}{*}{$\begin{array}{l}\text { Cat spoor } \\
(1000 \mathrm{~m} \\
\text { transect } \\
\text { segments, } \\
\left.k^{6}=3\right)\end{array}$} & $27.1(2.1)$ & & $5.9(1.7)$ & - & 8.59 & $58 \%(0.63)$ & 0.0 \\
\hline & $127(3.0)^{9}$ & & $6.9(1.8)$ & - & 9.69 & $60 \%(0.63)$ & 0.11 \\
\hline & $26.2(2.3)$ & spline & $5.9(1.7)$ & - & 9.17 & $60 \%(0.70)$ & 0.30 \\
\hline & $123(3.2)^{10}$ & spline & $6.9(1.8)$ & - & 11.15 & $62 \%(0.70)$ & 0.41 \\
\hline & $26.9(2.1)$ & - & $5.7(1.8)$ & $1.07(1.6)$ & 9.26 & $59 \%(0.63)$ & 0.59 \\
\hline & $127(3.0)^{11}$ & - & $6.7(1.8)$ & $1.08(1.6)$ & 10.36 & $61 \%(0.64)$ & 0.89 \\
\hline & $26.0(2.3)$ & spline & $5.7(1.8)$ & $1.07(1.6)$ & 10.72 & $61 \%(0.70)$ & 0.89 \\
\hline & $123(3.2)^{12}$ & spline & $6.7(1.8)$ & $1.08(1.6)$ & 11.81 & $63 \%(0.70)$ & 0.99 \\
\hline & $47.0(2.5)^{13}$ & spline & $5.7(1.8)$ & 1.1 (1.6) & 11.67 & $63 \%(0.68)$ & 1.23 \\
\hline \multirow{4}{*}{$\begin{array}{l}\text { Fox spoor } \\
(100 \mathrm{~m} \\
\text { transect } \\
\text { segments, } \\
\left.k^{6}=3\right)\end{array}$} & $910(2.2)$ & spline $^{7}$ & $7.2(1.8)$ & $0.13(2.7)$ & 10.38 & $49 \%(0.20)$ & 0.00 \\
\hline & $788(2.3)^{14}$ & spline & $7.1(1.8)$ & $0.05(4.4)$ & 12.51 & $50 \%(0.22)$ & 0.62 \\
\hline & $712(3.7)^{15}$ & spline & $6.9(1.9)$ & $0.13(2.7)$ & 12.38 & $49 \%(0.20)$ & 1.94 \\
\hline & $892(2.2)$ & spline & $5.0(2.0)$ & - & 13.1 & $50 \%(0.20)$ & 1.97 \\
\hline
\end{tabular}

Note: dashes indicate absence of variable in model; $\mathrm{n} / \mathrm{a}$ indicates a variable that was excluded from models in the model selection process due to the data being too sparse for testing this variable. 1: Models are of the form $y=e^{\wedge}$ (intercept $\left.+\beta 1^{*} x+\beta 2 * x 2 \ldots\right)$; all parameters and standard errors shown have been backward transformed for interpretability. 2: non-linear relationship modelled using thin-plate regression spline ('spline'). 3: traffic is a continuous variable reported as average vehicles per day. 4: df= total estimated degrees of freedom 5: The effect of road proximity could not be tested with the dingo camera data as there were too few off-road data points in this dataset. $6: k$ is the dimension of the basis used to represent the smooth term; it determines how 'flexible' the smoothing spline is. 7: See Fig.4 for predicted splines from optimal models. 8: interaction with traffic: traffic effect for on-road locations $\rightarrow 5.7$ (s.e. 3.7). 9: interaction with veg: on-road and woodland $\rightarrow-2.1$ (s.e. 4.4). 10: interaction with veg: on-road and woodland $\rightarrow 0.1$ (s.e. 4.5). 11: interaction w. veg: on-road and woodland $\rightarrow 0.12$ (s.e. 4.5). 12: interaction w. veg: on-road and woodland $\rightarrow 0.12$ (s.e. 4.5). 13: interaction w. traffic: traffic effects on-road $\rightarrow 0.002$ (s.e. 1.5). 14: interaction w. traffic: traffic effect on-road $\rightarrow 6.43$ (s.e. 5.1). 15: interaction w. veg: on-road and woodland $\rightarrow 1.32$ (s.e. 3.2). 


\subsection{Dingo activity}

Dingo activity was strongly biased toward roads, with $90 \%$ of all dingo observations occurring on-road. Onroad activity averaged 105 and 261 times the average off-road for the camera and spoor data respectively. The top-ranking models reflected this, with on/off-road status consistently included (Table 2). The camera data models indicated greater dingo activity in shrublands, although this primarily reflected on-road activity - there were only two off-road dingo observations via camera in shrublands.

The optimal spoor data model identified an effect of road proximity on dingo activity that varied with vegetation type. In shrublands off-road spoor observations were generally low and restricted to within 1 $\mathrm{km}$ from the road. In contrast, off-road spoor activity in woodlands peaked $\sim 2.5 \mathrm{~km}$ away from roads (Fig. 4a).

\subsection{Cat activity}

Cats showed the weakest preference for roads with only $21 \%$ of cat observations occurring on roads, although the chances of observing cat activity on-road were still 12 and 30 times greater than off-road, based on the camera and spoor datasets respectively. The top-ranking cat camera models indicated a strong effect of road proximity that varied with vegetation type: peaks in cat activity were predicted at approximately $1.5 \mathrm{~km}$ from roads in woodlands and $2.3 \mathrm{~km}$ from roads in shrublands (Fig. $4 \mathrm{~b}$ ). On/off-road status and traffic were both included in some top-ranking cat camera models, with large uncertainty around parameter estimates.

The cat spoor data indicated slightly different relationships. The top-ranking models indicated a strong, positive association between roads and cat spoor. Road proximity was not included in the optimal model; it did feature in other top-ranking models; but these did not include an interaction with vegetation type. All top-ranking cat spoor models indicated a positive association with woodlands, contrasting with the greater number of cats observed in shrublands on camera.

\subsection{Fox activity}

Three out of the four foxes recorded on camera were on roads, although this dataset was too small for statistical analysis. In contrast, fox spoor was the most abundant out of all the species. On-road fox spoor records were 150 times more frequent per unit area than off-road records and all the top-ranking models confirmed the strong association between fox spoor and roads. The effect of road proximity for off-road fox spoor was similarly strong, with models predicting greater fox activity immediately adjacent to roads and again at approximately $2 \mathrm{~km}$ away from roads, with a relative 'trough' in fox activity in between (Fig. 4c). Fox spoor models indicated greater activity in woodlands and a negative association with traffic, although uncertainty on estimates for the latter are high. 

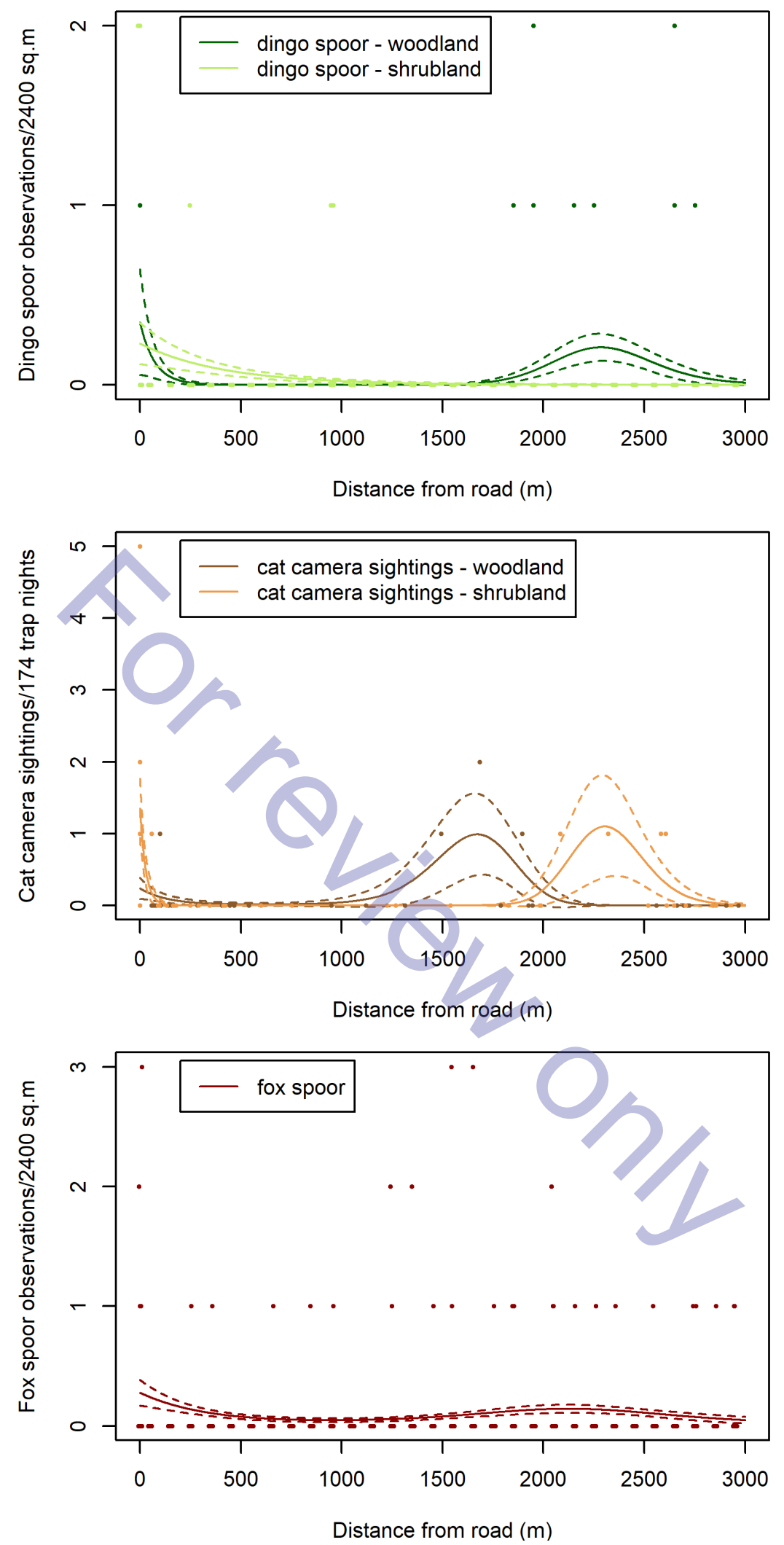

Figure 4: Thin-plate regression spline relationships between predator activity and distance from road for the optimal models which included this effect. Splines appear with or without interactions with vegetation type, as per the optimal model. Points indicate raw data. a) Dingo spoor, showing an interaction with vegetation type; b) feral cat camera data, showing an interaction with vegetation type; c) red fox spoor data; no interaction with vegetation type was included in the top-ranking models here. 


\section{Discussion}

Our results show that roads have a strong influence on the activity of all three predators studied. Road effects, either in the form of on-road versus off-road status or road proximity, appeared in every topranking statistical model. In the majority of cases, on-road predator activity was many times greater than off-road activity: findings which correspond with those of Towerton et al. (2011).

Out of the species studied, dingo and fox biases toward on-road activity were the strongest, whereas cat biases were equivocal. Thus, the results for dingoes and foxes support our first hypothesis that on-road activity would be greater than off-road activity. This hypothesis holds true for the cat spoor data, but only for woodlands using the cat camera data: in shrublands, the activity at $\sim 1600 \mathrm{~m}$ away from a road is greater than that predicted on-road. These findings mirror a previous study which indicated that while dingoes and foxes tend to walk along roads, cats were less likely to (Read \& Eldridge 2010).

Overall our second hypothesis, that activity of the three study predators would be greatest near roads and reach a lower 'background' level further away was rejected, except in the case of dingo activity in shrublands, as indicated by the spoor data, although data points are sparse and thus conclusions uncertain. The dingo camera data also suggest such a trend, though were too sparse to be analysed. For dingoes in shrublands, roads may facilitate access to otherwise relatively impenetrable or unattractive vegetation, or simply act as a strong concentrating force: dingo activity on shrubland roads was the highest recorded on cameras.

Plotted predictions of dingo spoor in woodlands, cat camera sightings in both woodlands and shrublands and fox spoor across both vegetation types indicated potential peaks in predator activity at distances 1.5-2.5 km away from roads. If these peaks are real ecological phenomena, we are unaware of mechanisms which may explain them. To our knowledge such off-road aggregations of species have only been reported once before (Fortin et al. 2013) with no explanation of their underlying mechanisms. Possible explanations may include prey aggregations away from roads or increased predator activity at territory boundaries, which may be aligned in respect to roads. However, these results are based on sparse datasets and thus may not represent actual ecological phenomena. They may be an artefact of the methodology or an unrecorded variable, or may be weak signals with statistical significance but no real ecological meaning.

Overall, it is not clear what the 'background rate' of activity for any species is, or if in fact such a rate exists. Nevertheless, our data suggest that all predators are also active to a degree away from roads (except possibly dingoes in shrublands).

Our third hypothesis, that the effects of roads would be more pronounced in shrublands than woodlands, was not consistently supported. The top-ranking dingo spoor models did provide support for this 
hypothesis, indicating that in shrublands activity is largely restricted to roads, whereas there is substantial off-road dingo activity in woodlands. This may mean that dingoes move more easily through woodlands than shrublands and that roads facilitate dingo access to shrubland areas that they otherwise would not frequent. Cat spoor was observed 121 and 16 times more frequently per unit area on-road compared with off-road, in shrublands and woodlands respectively, also indicating an effect of vegetation on road preference, and this was reflected by some top-ranked models. Still, the camera data demonstrate that cats do occur in shrublands at great distances from roads, so it is unlikely that they require roads to access these areas. For the remaining datasets, there were either only minor interactions between vegetation and road effects (cat camera data); an interaction effect opposite of that hypothesised, whereby road bias is greater in woodlands (fox spoor data), or insufficient off-road data was available to test for the interaction (dingo camera data).

Traffic was low and variable across the study area and generally appeared to be a minor predictor with large uncertainty around its effect estimates. Where included in the top-ranking models, estimates indicated a reduction in dingo and fox activity with increasing traffic, suggesting that dingoes and foxes may tend to avoid roads with more traffic. The traffic effect is mixed for the cat models with most topranking spoor models indicating a positive traffic effect, and one camera model indicating a negative effect.

\subsection{Ecological considerations}

If animal movements can be viewed as tactics to optimise the efficiency with which animals exploit their habitats (Brody \& Pelton 1989), it certainly appears that the species studied gain substantial benefits from road use. Such benefits may include more efficient hunting and travel and easier navigation (James 1999; Avgar et al. 2013; Doherty et al. 2015). However, it is not apparent whether these benefits lead to overall increases in numbers of predators or predation pressure in roaded areas, or simply a concentration of activity along roads.

Concentrations of predator activity along a road can result in increased direct predation pressure on local prey species. It can also result in effective habitat loss or reduction in habitat quality where prey species wholly or partly avoid adjacent areas (Brown et al. 1999; James 1999). For prey species that persist within a road effect zone that has elevated predation rates, the increased predation risk can detriment physically: chronic stress, reduced feeding, suppressed breeding and reduced fertility (Avgar et al. 2013; Boonstra 2013). Elongated areas of high predator activity may also effectively create semi-permeable barriers to movement for prey species (Beyer et al. 2014).

Roads may also provide more direct access to areas where predators do not usually hunt, allowing predators to penetrate further into the range of species that may be more sensitive to predation than prey species in the predator's regular habitat (James 1999). This may be the case for dingoes in shrublands and 
may also partially explain why foxes and cats (which appear to penetrate shrublands more than dingoes) have been more devastating to small mammals than the original dingo populations.

This paper has focused on predator activity as a surrogate for predation pressure or risk and not on estimating actual predator abundances. Abundances are often difficult to estimate for elusive and often solitary animals (Bengsen et al. 2011) and abundance measures alone may not reflect the full effect of roads. This is because distribution and movement patterns of predators may result in encounter rates for prey species that are not directly proportional to their densities (Skogland 1991; James 1999). Abundance may simply indicate average predation pressure over a larger area and not reflect important finer-scale changes in predation dynamics, and thus, predator activity may be more useful (and easier to measure) for determining road impacts.

\subsection{The value of multiple measurement methods}

The two different methodologies largely complemented each other and yielded similar results overall. However, some differences between results from camera and spoor data were evident, possibly reflecting differences in detectability between the different methodologies (discussed in detail in Online Appendix 1). Despite a general agreement between our observations and findings reported in the literature, there were also some differences, which may also point to differences in detectability. In contrast with Vine et al. (2009) who concluded that cameras were amongst the most efficient methods for detecting foxes, our fox camera data were too sparse to be analysed at all, although our fox spoor data were the most abundant amongst the species studied. Previous work has indicated that animals can detect cameras (Meek et al. 2014) and in our study foxes may have avoided cameras and/or the human scent that may have remained on them.

Differences between observations based on different methodologies suggest that the results obtained from one method may not represent the whole picture of predator activity in an area. While several measures were implemented in this study to address potential detectability issues, some potential detectability issues could not be addressed sufficiently to rule them out (Online Appendix 1). However, we suggest that our approach of using a combination of different methodologies is a powerful way of overcoming this issue, as the consistency of trends across different methodologies (each with different detectability issues) provides an indication of how robust these trends are.

For example, apart from some of the cat camera models, on-road activity was many times higher across the different methodologies, as well as across the species studied, indicating that this trend is unlikely to be simply an artefact of methodology biases. Even within the 'spoor survey' methodology, the inclusion of both scat and print observations minimised potential detectability biases (e.g. softer ground surfaces may have been more likely to retain animal prints, but scats may also have been more frequently covered or 
buried by softer soils: biases that may have at least partially cancelled each other out). In any case, biases associated with soil texture are unlikely to affect observations from camera surveys.

We argue, therefore, that it may be worth considering combining multiple monitoring methodologies where possible, at least until a single best method is identified for a given situation. While logistical or budgetary constraints might militate against this, in this study the spoor surveys generated a substantial amount of useful data while only minimally adding to the time and money that was required to service the motion sensor-cameras. Combining methodologies would also be valuable for predator species which are often cryptic and require large monitoring efforts to obtain sufficient data for analysis. Research into what detectability biases exist, and how they can be managed or accounted for, would benefit such approaches. Research into the equivalence of datasets based on different methodologies, that would allow such datasets to be combined, would also be valuable. These insights have important implications for the field of ecological monitoring in which there is currently a strong movement towards the use of motion-sensor cameras to the exclusion of other monitoring methods.

\subsection{Broader implications for further research and management}

The recent proliferation of literature aimed at understanding and mitigating the environmental impacts of infrastructure expansion reflects a burgeoning concern around the rapidity and pervasiveness of this expansion (e.g. Laurance et al. 2015). Our analysis contributes valuable insights into the implications of this trend for both native and invasive predators, although further research is required into the consequences of these trends for prey species.

Our study has demonstrated that even unbladed roads with little or no traffic through open, permeable vegetation have significant effects on predator activity and these effects may extend for a few kilometres into the surrounding vegetation. Although the effects of unsealed vehicle tracks may in many cases be smaller than those of large roads, unsealed vehicle tracks commonly make up a large component of linear infrastructure networks in relatively intact areas (Raiter et al. 2017).

Options for mitigating impacts of roads include avoiding the creation of new roads in intact landscapes and careful consideration of routing for roads that cannot be avoided, to maintain large trackless areas where possible. Also, consolidating existing road networks and rehabilitating abandoned or unneeded roads can help to reduce impacts. Compensatory schemes could require projects which entail the creation of new roads to rehabilitate at least an equivalent distance of roads elsewhere within that region.

This investigation also offers insights for species conservation, invasive predator control and monitoring programs. For example, where conservation of a prey species requires predator control, rehabilitating roads in that area may be a more effective long-term strategy than baiting it. Also, where invasive predators in an area are found to frequent roads, control efforts could be optimised by targeting control 
efforts (e.g. baiting or trapping) to roads. Monitoring approaches and management decisions based on studies that focus monitoring on or near roads should consider that those studies may present an unrepresentative picture of fauna activity in the landscape.

The effects of roads on predator activity in relatively intact landscapes are part of a suite of indirect or enigmatic impacts that are not systematically accounted for in impact evaluations and that can, in sum, often be worse than the direct impacts of the infrastructure (e.g. habitat clearing). These impacts need to be incorporated into ecological impact evaluations; otherwise they can undermine the potential for successful impact mitigation (Raiter et al. 2014; Laurance et al. 2015).

\section{Declaration of competing Interest}

The authors listed above certify that they have NO actual or potential competing interests which may influence the approach, methods, results or discussion reported in this manuscript. No part of the research has been published in any form elsewhere, except in K. Raiter's PhD Thesis entitled: 'Enigmatic ecological impacts of mining and linear infrastructure development in Australia's Great Western Woodlands' available at:

https://api.researchrepository.uwa.edu.au/portalfiles/portal/10146368/THESIS DOCTOR OF PHILOSOPHY RAITER Keren

Gila 2016.pdf.

\section{Acknowledgements}

K.G.R. was a recipient of the Gledden Postgraduate Research Award and received funding from The Wilderness Society, Australia Research Council Centre of Excellence for Environmental Decisions and Gondwana Link during this study. We gratefully acknowledge support from the Great Western Woodlands Supersite (part of Australia's Terrestrial Ecosystem Research Network), Cliffs Natural Resources and the National Environmental Research Network's Environmental Decisions Hub. We thank the intrepid field volunteers: Fiona Westcott, Kieran Golby, Stewart Bayford, Neal Birch, Ophir Levin, Bridget Johnson, Rebecca Campbell, Joanna Burgar and Michael Wysong for their assistance and Simon Wood, creator of 'mgcv' for helpful advice on the data analysis. We also thank Richard Forman, Andrew Bennett, John Bissonette, Micah Davies and two anonymous reviewers for constructive comments on earlier versions of this manuscript. All work was carried out under University of Western Australia Animal Ethics Committee permit RA/3/600/26 and Department of Biodiversity, Conservation and Attractions (Parks and Wildlife Service) permits SF009357 and CE004036.

\section{References}

Avgar T, Mosser A, Brown GS, Fryxell JM. 2013. Environmental and individual drivers of animal movement patterns across a wide geographical gradient. Journal of Animal Ecology 82:96-106. 
Basille M, Van Moorter B, Herfindal I, Martin J, Linnell JDC, Odden J, Andersen R, Gaillard J-M. 2013. Selecting habitat to survive: the impact of road density on survival in a large carnivore. PLoS ONE 8:e65493.

Bengsen A, Algar D, Ballard G, Buckmaster T, Comer S, Fleming P, Friend J, Johnston M, McGregor H, Moseby K. 2016. Feral cat home-range size varies predictably with landscape productivity and population density. Journal of Zoology 298:112-120.

Bengsen A, Butler J, Masters P. 2011. Estimating and indexing feral cat population abundances using camera traps. Wildlife Research 38:732-739.

Beyer HL, Gurarie E, Borger L, Panzacchi M, Basille M, Herfindal I, Van Moorter B, Lele S, Matthiopoulos J. 2014. "You shall not pass!": quantifying barrier permeability and proximity avoidance by animals. Journal of Animal Ecology 85:43-53.

Boonstra R. 2013. Reality as the leading cause of stress: rethinking the impact of chronic stress in nature. Functional Ecology 27:11-23.

Brody AJ, Pelton MR. 1989. Effects of roads on black bear movements in western North Carolina. Wildlife Society Bulletin 17:5-10.

Brook LA, Johnson CN, Ritchie EG. 2012. Effects of predator control on behaviour of an apex predator and indirect consequences for mesopredator suppression. Journal of applied ecology 49:1278-1286.

Brown JS, Laundré JW, Gurung M. 1999. The Ecology of Fear: Optimal Foraging, Game Theory, and Trophic Interactions. Journal of Mammalogy 80:385-399.

Carter A, Luck GW, McDonald SP. 2012. Ecology of the red fox (Vulpes vulpes) in an agricultural landscape. 2. Home range and movements. Australian Mammalogy 34:175-187.

Cavallini P. 1994. Faeces count as an index of fox abundance. Acta Theriologica 39:417-424.

DeGregorio BA, Weatherhead PJ, Sperry JH. 2014. Power lines, roads, and avian nest survival: effects on predator identity and predation intensity. Ecology and Evolution 4:1589-1600.

Dixon BG. 1997. Cumulative effects modeling for grizzly bears in the Greater Yellowstone Ecosystem. Montana State University, Bozeman, Montana, USA.

Doherty TS, Dickman CR, Nimmo DG, Ritchie EG. 2015. Multiple threats, or multiplying the threats? Interactions between invasive predators and other ecological disturbances. Biological Conservation 190:60-68.

Fleming PJ, Corbett L, Harden R, Thomson P 2001. Managing the impacts of dingoes and other wild dogs. Bureau of Rural Sciences and Natural Heritage Trust, Canberra.

Forman RTT, et al. 2003. Road ecology: science and solutions. Island Press, Washington.

Fortin D, Buono P-L, Fortin A, Courbin N, Gingras CT, Moorcroft PR, Courtois R, Dussault C. 2013. Movement Responses of Caribou to Human-Induced Habitat Edges Lead to Their Aggregation near Anthropogenic Features. The American Naturalist 181:827-836.

Grilo C, Smith DJ, Klar N. 2015. Carnivores: struggling for survival in roaded landscapes. Page 300 in van der Ree R, Smith DJ, and Grilo C, editors. Handbook of Road Ecology. John Wiley \& Sons, Chichester, UK.

Harmsen BJ, Foster RJ, Silver S, Ostro L, Doncaster CP. 2010. Differential use of trails by forest mammals and the implications for camera-trap studies: a case study from Belize. Biotropica 42:126-133.

Jaeger JAG. 2015. Improving environmental impact assessment and road planning at the landscape scale. Pages 32-42 in van der Ree R, Smith DJ, and Grilo C, editors. Handbook of Road Ecology. John Wiley \& Sons, Ltd, Chichester, UK. 
James ARC. 1999. Effects of industrial development on the predator-prey relationship between wolves and caribou in Northeastern Alberta. Department of Biological Sciences. University of Alberta, Alberta.

James ARC, Stuart-Smith AK. 2000. Distribution of Caribou and Wolves in Relation to Linear Corridors. The Journal of Wildlife Management 64:154-159.

Latham ADM, Latham MC, Boyce MS, Boutin S. 2011. Movement responses by wolves to industrial linear features and their effect on woodland caribou in northeastern Alberta. Ecological Applications 21:2854-2865.

Laundré JW, Hernández L, López Medina P, Campanella A, López-Portillo J, González-Romero A, GrajalesTam KM, Burke AM, Gronemeyer P, Browing DM. 2013. The landscape of fear: the missing link to understand top-down and bottom-up controls of prey abundance? Ecology 95:1141-1152.

Laurance WF. 2018. Conservation and the Global Infrastructure Tsunami: Disclose, Debate, Delay! Trends in Ecology \& Evolution 33:568-571.

Laurance WF, Peletier-Jellema A, Geenen B, Koster H, Verweij P, Van Dijck P, Lovejoy TE, Schleicher J, Van Kuijk M. 2015. Reducing the global environmental impacts of rapid infrastructure expansion. Current Biology 25:R259-R262.

May SA, Norton T. 1996. Influence of fragmentation and disturbance on the potential impact of feral predators on native fauna in Australian forest ecosystems. Wildlife Research 23:387-400.

Mech LD, Fritts SH, Radde GL, Paul WJ. 1988. Wolf distribution and road density in Minnesota. Wildlife Society Bulletin 16:85-87.

Meek P, Ballard G, Fleming PJS 2012. An introduction to camera trapping for wildlife surveys in Australia. PestSmart Toolkit publication, Invasive Animals Cooperative Research Centre, Canberra, Australia.

Meek PD, Ballard G-A, Fleming PJ, Schaefer M, Williams W, Falzon G. 2014. Camera Traps Can Be Heard and Seen by Animals. PloS one 9:e110832.

Meek PD, Saunders G. 2000. Home range and movement of foxes (Vulpes vulpes) in coastal New South Wales, Australia. Wildlife Research 27:663-668.

Molsher R, Dickman C, Newsome A, Müller W. 2005. Home ranges of feral cats (Felis catus) in centralwestern New South Wales, Australia. Wildlife Research 32:587-595.

Moseby K, Nano T, Southgate R, Australia S 2009. Tales in the sand: a guide to identifying Australian arid zone fauna using spoor and other signs. Ecological Horizons, Kimba, Australia.

Palmer MS, Fieberg J, Swanson A, Kosmala M, Packer C. 2017. A 'dynamic' landscape of fear: prey responses to spatiotemporal variations in predation risk across the lunar cycle. Ecology Letters 20:1364-1373.

Prober S, et al. 2012. Facilitating adaptation of biodiversity to climate change: a conceptual framework applied to the world's largest Mediterranean-climate woodland. Climatic Change 110:227-248.

Prugh LR, Golden CD. 2014. Does moonlight increase predation risk? Meta-analysis reveals divergent responses of nocturnal mammals to lunar cycles. Journal of Animal Ecology 83:504-514.

R Core Team. 2018. R: A Language and Environment for Statistical Computing. R Foundation for Statistical Computing, Vienna, Austria.

Raiter KG, Hobbs RJ, Possingham Hugh P, Valentine LE, Prober SM. 2018a. Predator activity associated with linear infrastructure in PANGAEA, editor.

Raiter KG, Possingham HP, Prober SM, Hobbs RJ. 2014. Under the radar: mitigating enigmatic ecological impacts. Trends in Ecology \& Evolution 29:635-644. 
Raiter KG, Prober SM, Hobbs RJ, Possingham HP. 2017. Lines in the sand: quantifying the cumulative development footprint in the world's largest remaining temperate woodland. Landscape Ecology 32:1969-1986.

Raiter KG, Prober SM, Possingham HP, Westcott F, Hobbs RJ. 2018b. Linear infrastructure impacts on landscape hydrology. Journal of Environmental Management 206:446-457.

Read J, Eldridge S. 2010. An optimised rapid detection technique for simultaneously monitoring activity of rabbits, cats, foxes and dingoes in the rangelands. The Rangeland Journal 32:389-394.

Salo P, Korpimäki E, Banks PB, Nordström M, Dickman CR. 2007. Alien predators are more dangerous than native predators to prey populations. Proceedings of the Royal Society of London B: Biological Sciences 274:1237-1243.

Skogland T. 1991. What are the effects of predators on large ungulate populations? Oikos 61:401-411.

Stephens D. 2015. Death by sex in an Australian icon: a continent-wide survey reveals extensive hybridisation between dingoes and domestic dogs. Molecular Ecology 24:5643-5656.

Suring LH, Barber KR, Schwartz CC, Bailey TN, Shuster WC, Tetreau MD. 1998. Analysis of cumulative effects on brown bears on the Kenai Peninsula, Southcentral Alaska. Ursus 10:107-117.

Towerton AL, Penman TD, Kavanagh RP, Dickman CR. 2011. Detecting pest and prey responses to fox control across the landscape using remote cameras. Wildlife Research 38:208-220.

Triggs B 2005. Tracks, scats, and other traces: a field guide to Australian mammals. Oxford University Press, Melbourne.

van der Ree R, Smith DJ, Grilo C. 2015a. The ecological effects of linear infrastructure and traffic. Pages 19 in van der Ree R, Smith DJ, and Grilo C, editors. Handbook of Road Ecology. John Wiley \& Sons, Ltd, Chichester, UK.

van der Ree R, Smith DJ, Grilo C, editors. 2015b. Handbook of Road Ecology. John Wiley \& Sons, Chichester, UK.

Vine S, Crowther M, Lapidge S, Dickman C, Mooney N, Piggott M, English A. 2009. Comparison of methods to detect rare and cryptic species: a case study using the red fox (Vulpes vulpes). Wildlife Research 36:436-446.

Watson A, Judd S, Watson J, Lam A, Mackenzie D 2008. The extraordinary nature of the Great Western Woodlands. The Wilderness Society, Perth.

Wood SN 2006. Generalized additive models: an introduction with R. CRC press

Wood SN. 2011. Fast stable restricted maximum likelihood and marginal likelihood estimation of semiparametric generalized linear models. Journal of the Royal Statistical Society (B) 73:3-36. 


\title{
Appendix 1 of 1 (Online Supplemental Material)
}

\section{Detectability and the value of complementary field assessments}

\author{
A1.1 Factors influencing detectability
}

Overall, the two different methodologies assessing predator activity (motion-sensor and spoor surveys) produced similar results, although there were some notable differences in trends observed, such as the contrasting importance and effects of on/off-road status and road proximity observed between camera and spoor data for cats. Differences in trends observed point to likely differences in detectability between the different methodologies. Several factors are likely to affect detectability including those listed in Table A1.

Table A1: Some factors likely to influence detectability for the two different monitoring methods Motion-sensor camera survey
whoidance of cameras and/or open spaces
remaining human scent, disturbance caused by
vegetation pruning, avoidance of clearings,
etc.), or preferences for and/or curiosity in
these locations. Spoor survey

Ground texture/ soil granulometry which may influence a) how easily an imprint is made b) how visible that print is to a human observer, and c) how long the print lasts in an identifiable form (e.g. clay holds prints for much longer than sand). Soil crusts may prevent prints from forming but if walked upon in wet conditions, may also hold prints for long periods of time.

Sensitivity of motion-sensor cameras (including Weather: rain and wind may wash or blow away prints or to speed and directionality of animal movement). Note: several camera trials were performed prior to the start of the investigations reported here and it was noted in most cases that some cameras failed to detect some animal movements, despite animal movements fulfilling stated detection requirements.

\footnotetext{
Ambient temperature (the cameras used in this investigation only detect motion of objects that are at temperatures substantially different from the ambient air temperature, as do most infra-red cameras). This means that animals with similar temperature to background are unlikely to be detected (common during warmer months). Ambient temperature can also affect detection range.
} leave them unidentifiable; and cover scats. Temperature and moisture/humidity may affect scat breakdown rates (scat breakdown rated in general, in these areas, are unknown).

Moist soil following rain is generally more likely to preserve print markings.

Camera failure, dysfunction, and theft. Note: all Speed of animal movement/animal weight distribution of these occurred infrequently during the reported survey.

may affect print markings, as well as other factors which
may affect rates at which spoor are left by animals -
defection rates may vary between animals walking along
tracks and animals walking through the vegetation
matrix, and this may vary between species (e.g. dingoes
and foxes are more likely to use scats as territory
markings, whereas cats are less likely to).

Ground-story vegetation may obscure spoor. Branches that move in the wind may 'sweep' ground of prints or 'sweep away' scats. Leaf litter and other plant debris can hide prints and scats and affect scat breakdown rates. 


\section{A1.2 Measures taken to minimise detectability issues}

We implemented the following measures to minimise the effect of variations in detectability on predator activity assessment results, for motion-sensor cameras:

- We used top-of-the range, covert, motion-sensor cameras with the fastest available trigger speed.

- We adjusted camera settings to maximise detectability (e.g. maximise range during night mode, at the cost of image quality and shutter speed, high trigger sensitivity, rapidfire picture intervals with 5 pictures per trigger, and no 'quiet period'). We also performed walk tests on all cameras to ensure they were detecting our movements after installing them at camera stations.

- We recorded the camera position along the transect (position 1=on-road; positions 2-5 = offroad, at increasing distances from roads) and randomly rotated cameras between camera positions every time cameras were relocated, such that a single camera was never positioned on-road or at the same off-road position twice; reducing potential bias associated with varying detection effectiveness between cameras.

- Where vegetation obscured part of the camera detection zone (all shrubland sites), the vegetation was pruned such that at least $80 \%$ of the detection zone was evident; equalising detectability across cameras. We tested visibility by having a subject walk across the camera detection zone at 8 and $16 \mathrm{~m}$ away from the camera and recording the percentage of 20 randomized locations where an object tied at a height of $10 \mathrm{~cm}$ was visible to an observer viewing from the same height and location of the camera.

- We pointed all cameras to within 45 degrees of south, to maximise and standardize detection rates (as per Meek et al. 2012).

- We repeatedly examined all camera detection zones for scats and prints to validate captured images with spoor data.

- We cased and locked on-road cameras and provided written explanations of their use written on every camera to minimise camera theft.

- In the single case where a camera was stolen, and in two cases where cameras malfunctioned, this was accounted for in the data analysis by reducing trap nights according to the amount of time the camera was out of action.

- We ran surveys for a longer period than what is generally reported in the literature -12 months - to maximise data collected and minimise the effects of detectability issues in certain seasons (e.g. potentially lower detectability during warmer ambient temperatures).

- We minimised any activities that would leave human scent or traces at or near transects, especially around camera stations. We also left substantial time frames between servicing cameras to allow for human scents to dissipate after a relatively short proportion of each monitoring duration.

We implemented the following measures to minimise the effect of variations in detectability on predator activity assessment results, for spoor surveys:

- We recorded both scats, prints, and other evidence of predator activity to minimise the detectability issues associated with each spoor type. For example, while prints may not be visible 
on hard ground, scats are likely to be more easily detectable and less easily covered/buried than on soft ground.

- We conducted a pilot study of soil granulometry variation, and recorded ground texture along transects to assess the degree to which ground surface texture varies along transect lengths and between on-road and off-road environments. While we did observe variations in ground surface texture, we found that overall the different textures were relatively evenly scattered throughout transects, and that the texture of the ground on-road was representative of at least a large proportion of the ground surface off-road. We concluded that the variation observed along the transects was too fine-scaled to incorporate into the analysis (e.g. soft, 'printable' hard ground for $50 \mathrm{~m}$; hard ground for $15 \mathrm{~m}$, moderately soft ground for $25 \mathrm{~m}$ etc.), particularly given the relatively sparse data and consequent limitations on statistical power for assessing relationships between soil granulometry and print detections.

- We noted that ground-storey vegetation was generally denser in shrublands compared to woodlands. We walked more slowly and observed more carefully in areas where vegetation made it more difficult to observe spoor on the ground, to even out to the extent possible the likelihood of detecting spoor in different ground-storey vegetation densities. We also suggest that the effect of increased 'printability' of softer shrubland ground surfaces may have somewhat offset the effect of decreased visibility of scats and prints.

- We conducted each round of spoor surveys within several days from beginning to end, surveying each transect in each round, to maximise consistency of prior weather conditions that may affect print detectability. On-road and off-road components of each transect were always surveyed immediately before or after each other. These would minimise any bias in results due to weather conditions.

\section{A1.3 Multiple methods to manage detection uncertainty}

We implemented several measures designed to minimise detection issues. Several other detection issues are unlikely to have affected the trends we observed by affecting all areas consistently (e.g. possible reduced animal detectability during high background temperature conditions on warm days). However, there remain some factors influencing detectability that may have affected our results, and that we couldn't account for in this study due to insufficient information (e.g. species defection rates on/off tracks) and/or insufficient statistical power (effect of fine-scale variations in soil granulometry along transects, particularly in comparison with on-road sections).

Differences between observations based on different methodologies suggest that the results obtained from one method may not represent the whole picture of predator activity in an area. While several measures were implemented in this study to address potential detectability issues, some factors affecting detectability could not be sufficiently addressed. We suggest that our approach of using a combination of different methodologies is a powerful way of overcoming this issue as the consistency of trends across different methodologies (each with their own detectability issues) provides an indication of the robustness of these trends.

For example, apart from some of the cat camera models, on-road activity was many times higher across the different methodologies, as well as across the species studied, indicating that this trend is unlikely to be simply an artefact of methodology biases. Even within the 'spoor survey' methodology, the inclusion of both scat and print observations minimised potential detectability biases (e.g. softer ground surfaces may have been more likely to retain animal prints, but scats may also have been more frequently covered or buried by softer soils: biases that may have at least partially cancelled each other out. In any case, biases associated with soil texture are unlikely to affect observations from camera surveys. 
We argue, therefore, that it may be worth considering combining multiple methodologies where possible, at least until a single best method is identified for a given situation. While logistical or budgetary constraints might militate against this, in this study the spoor surveys generated a substantial amount of useful data while only minimally adding to the time and money that was required to service the motion sensor-cameras. Combining methodologies would be particularly valuable for predator species which are often cryptic and require large monitoring efforts to obtain sufficient data for analysis. Research into what detectability biases exist, and how they can be managed or accounted for, would benefit such fauna monitoring. Research into the equivalence of such datasets, that would allow datasets based on different methods to be combined would also be valuable. These insights have important implications for the field of ecological monitoring in which there is currently a strong movement towards the use of motion-sensor cameras to the exclusion of other monitoring methods.

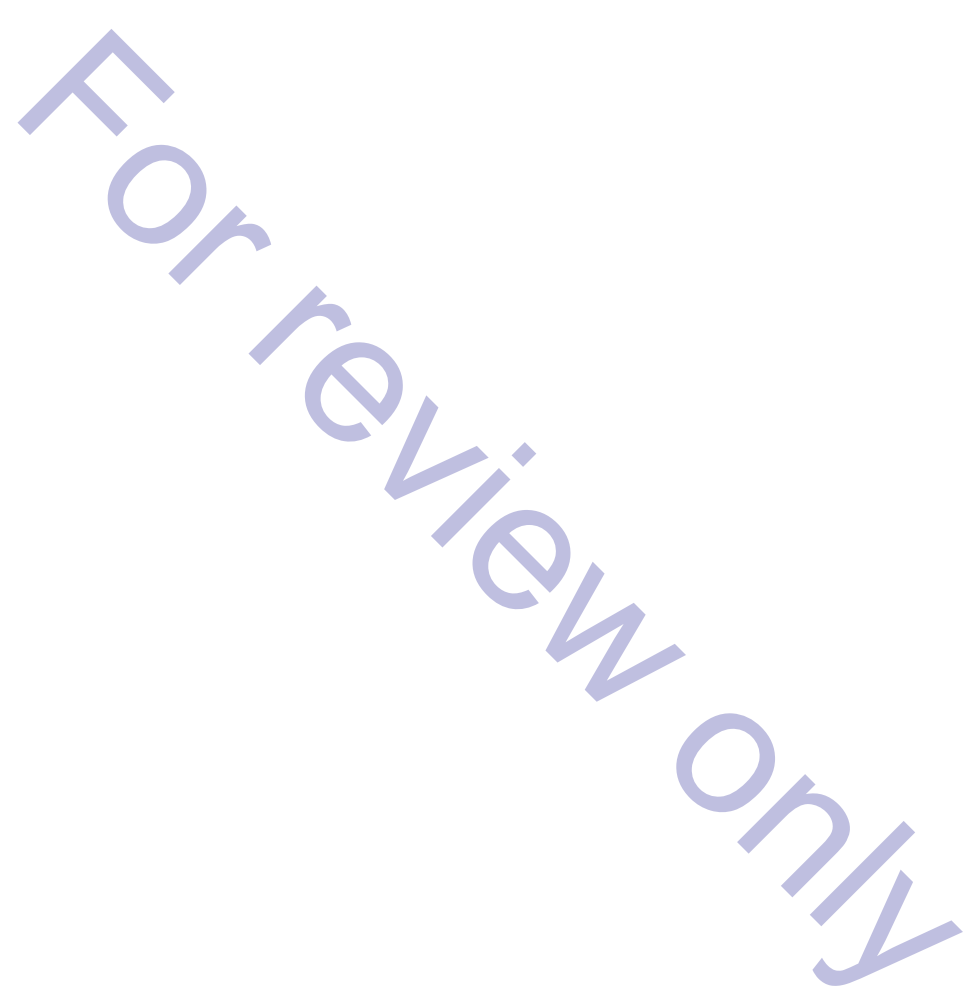

